Gut and Liver, Vol. 13, No. 1, January 2019, pp. 114-131

\title{
Alcohol Consumption Can Reduce the Risk of Gallstone Disease: A Systematic Review with a Dose-Response Meta-Analysis of Case-Control and Cohort Studies
}

\author{
Byung Hyo Cha ${ }^{1}$, Myoung-jin Jang ${ }^{2}$, and Sang Hyub Lee ${ }^{3}$ \\ ${ }^{1}$ Department of Gastroenterology, Division of Medicine, Sheikh Khalifa Specialty Hospital, Ras Al Khaimah, UAE, ${ }^{2}$ Medical Research \\ Collaborating Center, and ${ }^{3}$ Department of Internal Medicine, Seoul National University Hospital, Seoul National University College of Medicine, \\ Seoul, Korea
}

Background/Aims: Gallstone disease (GSD) is a common gastrointestinal disorder. Clinical epidemiological studies revealed that alcohol consumption has a preventive effect on the development of GSD. This study aimed to evaluate the relative risks of drinking for GSD development and investigate the dose-response relationships. Methods: A systematic search of the MEDLINE, EMBASE, and Cochrane Library databases for studies published up to 2018 was performed. All studies that satisfied the following eligibility criteria were included: patients with GSD with or without cholecystitis; and cohort or case-control studies investigating the association between alcohol consumption and GSD development. Results: Sixteen case-control studies including 24,401 gallstone cases and 76,185 controls, and eight cohort studies with 14,693 GSD cases among 2,432,471 person-years were enrolled. Alcohol consumption presented a decreased overall risk of GSD (pooled relative ratio [RR], 0.84; 95\% confidence interval $[\mathrm{Cl}], 0.79$ to $0.89 ; p=0.02$ ). Subgroup analyses according to drinking levels indicated a gradual risk reduction for GSD compared to nondrinkers (light: RR, 0.96; $95 \% \mathrm{Cl}, 0.94$ to $0.99 ; \mathrm{p}=0.75$; moderate: $\mathrm{RR}, 0.80 ; 95 \% \mathrm{Cl}$, 0.75 to $0.85 ; p=0.27$; high: RR, $0.66 ; 95 \% \mathrm{Cl}, 0.56$ to 0.79 ; $p<0.01)$. A nonlinear risk reduction was observed in a doseresponse meta-analysis of all the studies $(n=14, p<0.01$ for nonlinearity). Conclusions: In this systematic review with meta-analysis, alcohol consumption could decrease the risk of GSD, and the dose-response analysis revealed a dosedependent linear risk reduction and a weakened linear trend between alcohol consumption levels less than and greater than $28 \mathrm{~g} /$ day. (Gut Liver 2019;13:114-131)
Key Words: Gallstone disease; Alcohol drinking; Doseresponse relationship; Meta-analysis; Review

\section{INTRODUCTION}

Gallstone disease (GSD) is a common gastrointestinal disease with a spectrum of clinical presentations from asymptomatic silent gallstones to severe acute cholecystitis. The prevalence is reported to be $10 \%-15 \%$ in adults with risk factors including old age, female gender, obesity, metabolic syndrome, and chronic liver disease. ${ }^{1}$ Gallstones with or without cholecystitis are one of the most common reasons for hospital admission, and treatment by laparoscopic cholecystectomy has become more popular in recent years. The burden of GSD has increased in recent years, with direct and indirect costs of the disease estimated to be more than $\$ 6.2$ billion in the United States. ${ }^{2.3}$

Notwithstanding that alcohol consumption is a known risk factor for many chronic diseases and malignancies, ${ }^{4-6}$ there have been many clinical epidemiological studies regarding the negative correlation between alcohol consumption and GSD risk. Thereafter, two meta-analyses revealed that alcohol consumption has a preventive effect on the development of GSD, ${ }^{7,8}$ and Wang et al. ${ }^{8}$ presented a linear relationship with a $12 \%$ risk reduction with each $10 \mathrm{~g} /$ day increment of alcohol (relative ratio [RR], 0.88; 95\% confidence interval [CI], 0.84 to 0.92 ) in a doseresponse meta-analysis. This systematic review was carried out to define the optimal level of alcohol consumption to maximize the protective effect on GSD.

\footnotetext{
Correspondence to: Byung Hyo Cha

Department of Gastroenterology, Division of Medicine, Sheikh Khalifa Specialty Hospital, Truck Road, Ras Al Khaimah 6365, UAE

Tel: +971-56-385-3131, Fax: +971-7-244-4437, E-mail: doctorhyo@gmail.com

Received on June 16, 2018. Revised on August 31, 2018. Accepted on September 3, 2018.

pISSN 1976-2283 eISSN 2005-1212 https://doi.org/10.5009/gnl18278

Byung Hyo Cha and Myoung-jin Jang contributed equally to this work as first authors.

() This is an Open Access article distributed under the terms of the Creative Commons Attribution Non-Commercial License (http://creativecommons.org/licenses/by-nc/4.0) which permits unrestricted non-commercial use, distribution, and reproduction in any medium, provided the original work is properly cited.
} 


\section{MATERIALS AND METHODS}

Two authors (B.H.C. and M.J.J.) performed a comprehensive systematic search for published studies that aimed to evaluate the relationship between alcohol consumption and GSD risk.

\section{Search methods to identify studies}

A comprehensive, systematic search was conducted for published articles from database inception to March 01, 2018 using MEDLINE, EMBASE, and Cochrane Controlled Trials Register. We confined our search to only English publications. The MEDLINE search strategy was adapted for use in the other databases searched (Appendix 1). The reference lists of retrieved articles were also examined for additional, eligible studies.

\section{Selection criteria}

Studies were included if they met the following criteria: (1) cohort or case-control studies published as original articles (abstracts, letters, reviews, and meta analyses were excluded); (2) studies reporting the relative risks (odds ratio [OR], RR, or hazard ratio [HR]) between alcohol consumption and GSD or sufficient data to calculate them. Case-control studies were excluded if drinking categories were based on alcohol consumption at the time of interview. ${ }^{9}$ When studies with overlapping populations were identified, the most appropriate study for this comparison was selected in terms of bias. When additional information was required, we contacted the corresponding authors of the study.

\section{Data extraction}

Data extraction was completed by two authors (B.H.C. and M.J.J.) independently from all included studies with a predefined information sheet, in accordance with the PRISMA (Preferred Reporting Items for Systematic Reviews and Metaanalyses). ${ }^{10}$ Any discrepancies in extracted data were resolved through consensus or discussion with a third author (S.H.L.). The following information was taken from each article: publication year, country, study design, sample size, age, gender, endpoint definition (cholelithiasis, GSD, cholecystitis, or cholecystectomy from calculous cholecystitis), the number of cases and controls or number of events and subjects at risk/person-years, risk ratio estimates with 95\% CIs, and covariates adjusted in the statistical analysis. The adjusted RRs were extracted and when they were not available, and unadjusted RRs and 95\% CIs were extracted or calculated.

\section{Quality assessment}

The overall study quality was assessed independently by two authors (B.H.C. and M.J.J.) using the Newcastle-Ottawa Scale (NOS) for case-control and cohort studies. ${ }^{11}$ The NOS consists of three domains: selection (four items, one star each), comparability (one item, up to two stars), and outcome (three items, one star each). Nine stars on the NOS reflects the highest quality.
Studies with a NOS score of 7 to 9 and less than 7 were considered to have a low and high risk of bias, respectively. Any disagreements between the reviewers were resolved through discussion (Appendix 2).

\section{Statistical analysis}

The association between alcohol consumption and the risk of GSD was examined on the basis of the pooled relative risks and their 95\% CIs. For the pooling analysis, alcohol consumption was converted into grams of ethanol per day using the standard drink size provided by the study or the conversion factors $(0.8$ $\mathrm{g} / \mathrm{mL}, 28.35 \mathrm{~g} / \mathrm{oz}, 14 \mathrm{~g} /$ drink, and $7.9 \mathrm{~g} /$ unit). The drinking level for each RR was assigned as the median or mean amount (in grams) of alcohol intake in each exposure category. When the median or mean intake per category was not reported, the midpoint of the upper and lower boundaries in each category was given. For the open-ended upper boundary, a value of 1.2 times the lower boundary was assigned to the category. ${ }^{12}$ For the open-ended lower boundary, the lower boundary was assumed to be zero. Nondrinking was considered as the reference category. There are several published guidelines defining moderate, heavy and binge drinking levels according to standard drinking definition: 1-2 drinks/day (7-14 g/day), more than 2 drinks/ day (>14 g/day), and 4-5 drinks/day (28-35 g/day). ${ }^{13-15}$ Based on those criteria, we classified consumption into light, moderate and high drinking as follows: $<7,7-14$, and $>14 \mathrm{~g} /$ day for women and $<14,14-28$ and $>28 \mathrm{~g} /$ day for men, respectively. For the studies in which the lowest category included both nondrinking and light drinking, the lowest category was used as the reference category. If there was more than one RR for each drinking category defined for this study, the study-specific risk estimates were combined with the Hamling et al. ${ }^{16}$ if the numbers of cases and person-years or numbers for each nondrinking and drinking group were available or calculable; otherwise, the data were pooled with inverse variance weighting. For studyspecific RR for overall drinking compared to nondrinking, the RR was estimated by pooling all RRs for the drinking categories defined in each study using the same method as described above. For the study reporting RR per drinking unit, RR for overall drinking was estimated by the RR at the mean or median drinking unit in the study, as the power of RR by the mean or median value. When raw data were available, all necessary RRs were obtained from analysis of the raw data. For the association of alcohol consumption and risk of GSD, pooled RRs among studies and their 95\% CIs and p-values were calculated using the random-effects model. Statistical heterogeneity between the studies was assessed with Cochran Q-test and $\mathrm{I}^{2}$ statistics. $\mathrm{I}^{2}$ values of 25\%, 50\% and 75\% have been suggested to be indicators of low, moderate, and high heterogeneity, respectively. ${ }^{17}$ Subgroup analysis was performed on study design and participant sex. Heterogeneity between subgroups was assessed using Cochran Q-test. Funnel plots and Egger tests for asymmetry 
were applied to assess the possibility of publication bias among the studies. To examine the dose-response association between alcohol consumption and GSD risk, 2-stage, random-effects, dose-response meta-analyses were performed. ${ }^{18,19}$ First, a studyspecific restricted cubic spline model with four knots at the fixed 5th, 35th, 65th, and 90th percentiles of alcohol consumption levels was estimated using generalized least square regression accounting for the correlation between estimates within each study. Second, study-specific estimates were pooled using the restricted maximum likelihood method in a random-effects meta-analysis. A p-value for nonlinearity was calculated by testing the null hypothesis that the regression coefficients of the spline transformations are all equal to zero. The predicted RR of alcohol intake was estimated based on the linear or restricted cubic splines. Statistical analyses were performed using STATA version 12.0 (Stata Corporation, College Station, TX, USA) or R version 3.4.1 (The R Foundation for Statistical Computing, Vienna, Austria). Two-sided p-values $<0.05$ were considered to be statistically significant.

\section{RESULTS}

\section{Description of studies}

In total, 190 articles were identified as relevant by an initial search strategy, and 47 duplicated cases were removed (Fig. 1). One hundred and twenty-six articles were excluded during screening for eligibility due to unmatched enrollment criteria. Finally, 17 articles that met the inclusion criteria were selected. The article of Thijs et al. ${ }^{20}$ had four case-control studies (studies A, B1, B2, and B3). Among the four studies, study A was not included for this meta-analysis because its cases or controls over- lapped those of the other two studies (studies B1 and B3), and the study design was more susceptible to protopathic bias than the other studies were. Of these, three articles (Scragg et al., ${ }^{21}$ Rhodes and Venables, ${ }^{22}$ Banim et al. ${ }^{23}$ ) reported the effects of drinking by gender, in one study by Cha et al., ${ }^{24}$ the effects by gender were calculated from raw data, and one article ${ }^{25}$ reported the sex-adjusted effects in both sex groups and the effects for females only. Lastly, a total of 24 studies (16 case-control studies and 8 cohort studies) were included in this meta-analysis study.

The summary of baseline characteristics is described in Table $1 .^{20-36}$ In total, 24,401 patients with gallstones and 76,185 controls were estimated from 16 case-control studies, and 14,693 cases of GSD developed among 2,432,471 person-years in eight cohort studies. Among the 24 enrolled studies, six reported their estimates in female-only groups, another four in maleonly groups, and the other 14 studies reported data on both sex groups. The majority of selected studies were performed in the USA and Europe, while four were in Asia, and one was in Australia. Each study provided adjusted risk measurements regarding different confounding factors.

\section{Quality of the included studies}

The NOS scores of the 24 included studies ranged from 6 to 9 stars (Appendixes 2 and 3). Eight of the 24 studies had a NOS score of 9 , seven studies had a score of 8 , where scores of 8 were given to seven studies because two studies used self-report for ascertainment of exposure (zero stars in assessment of exposure), and five studies controlled for important factors (only one star in comparability domain). Three studies were scored as 7 , with no stars in items of representativeness of study population,

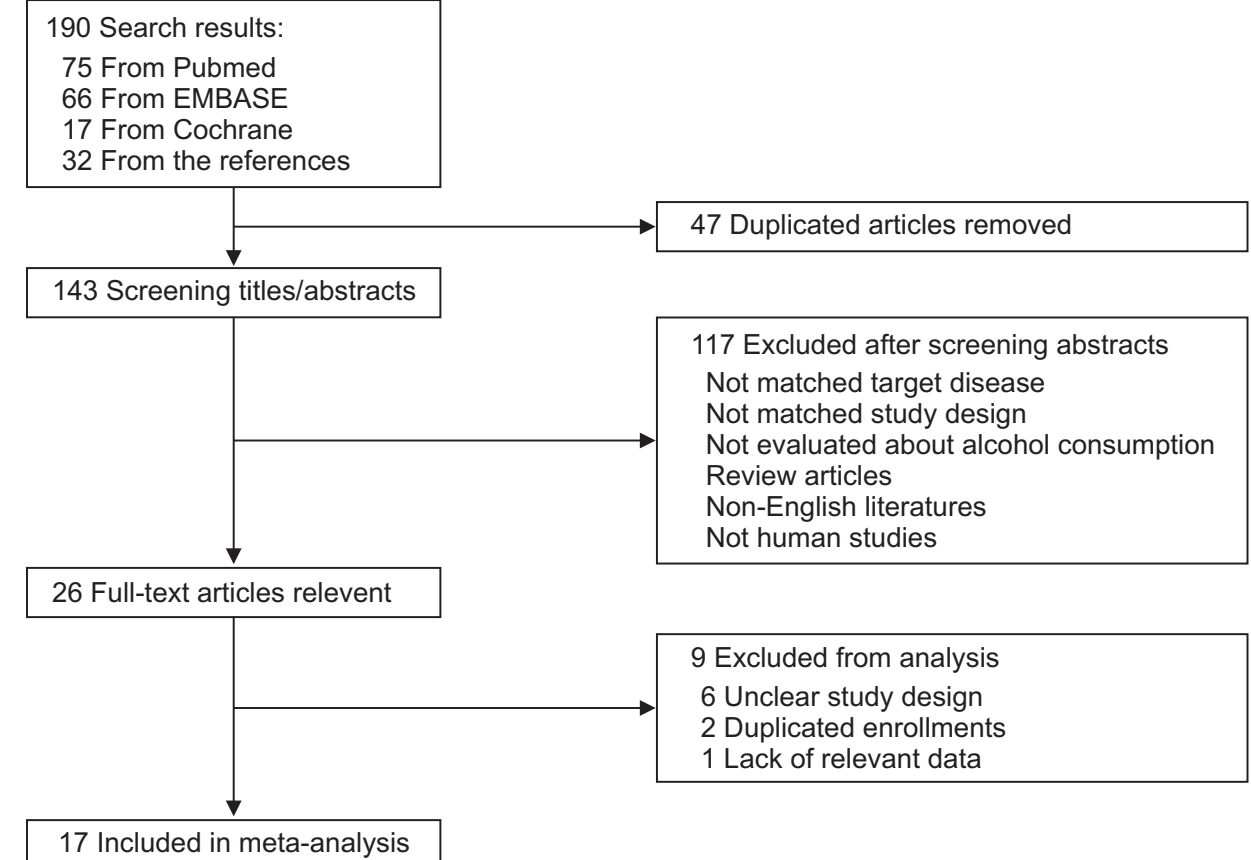

Fig. 1. Flowchart of Study Selection for Inclusion in Meta-analysis. 


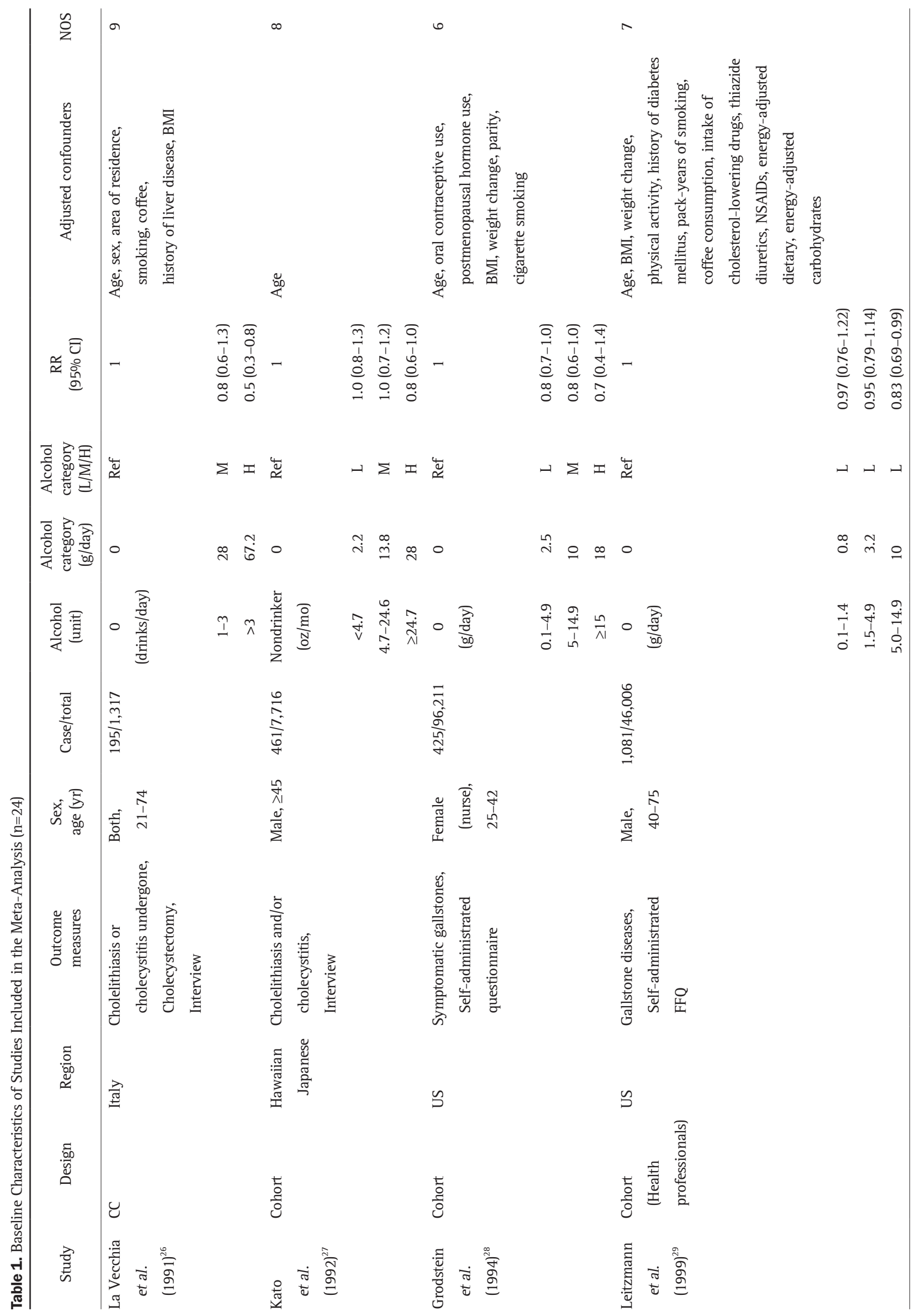




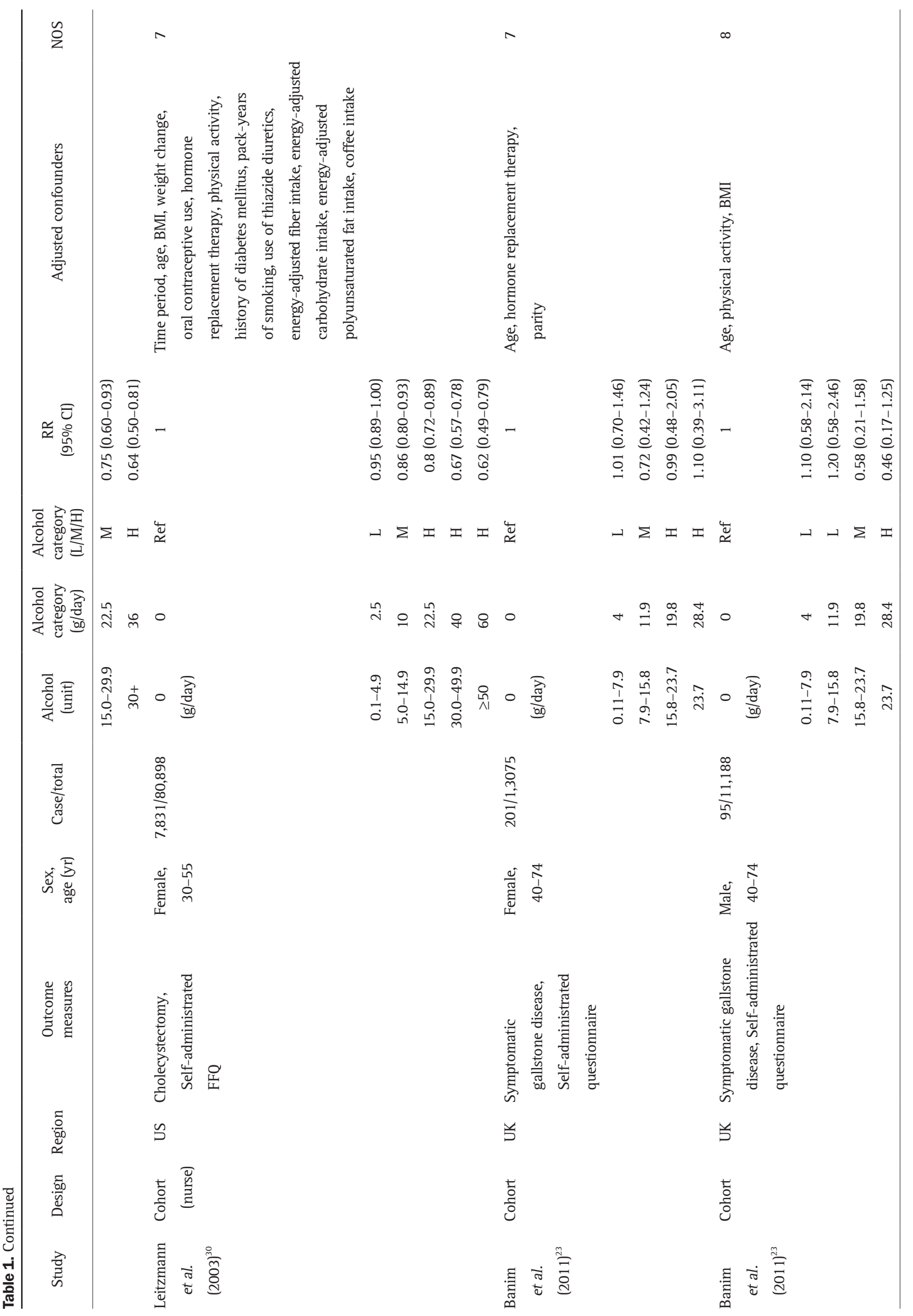




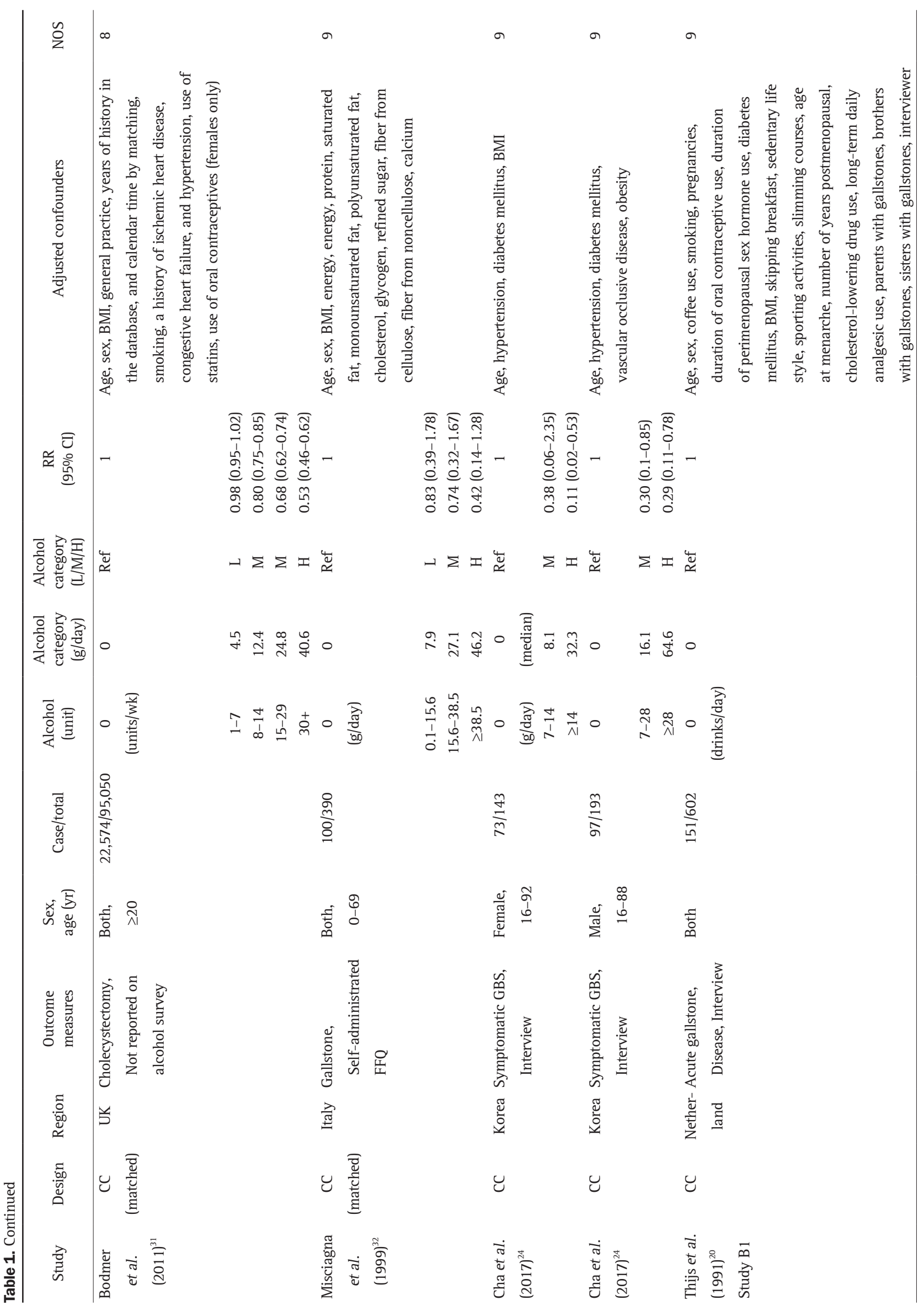




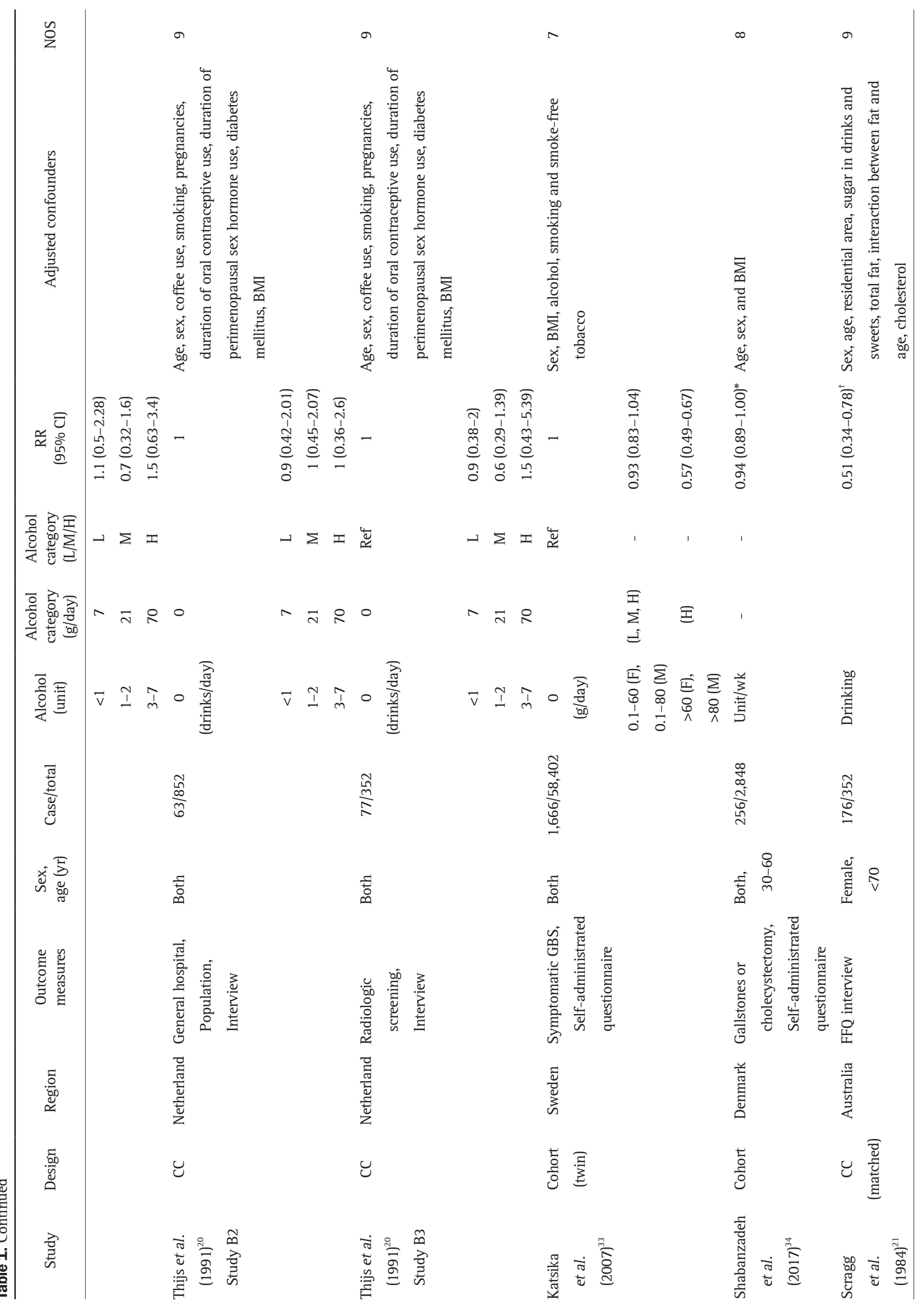




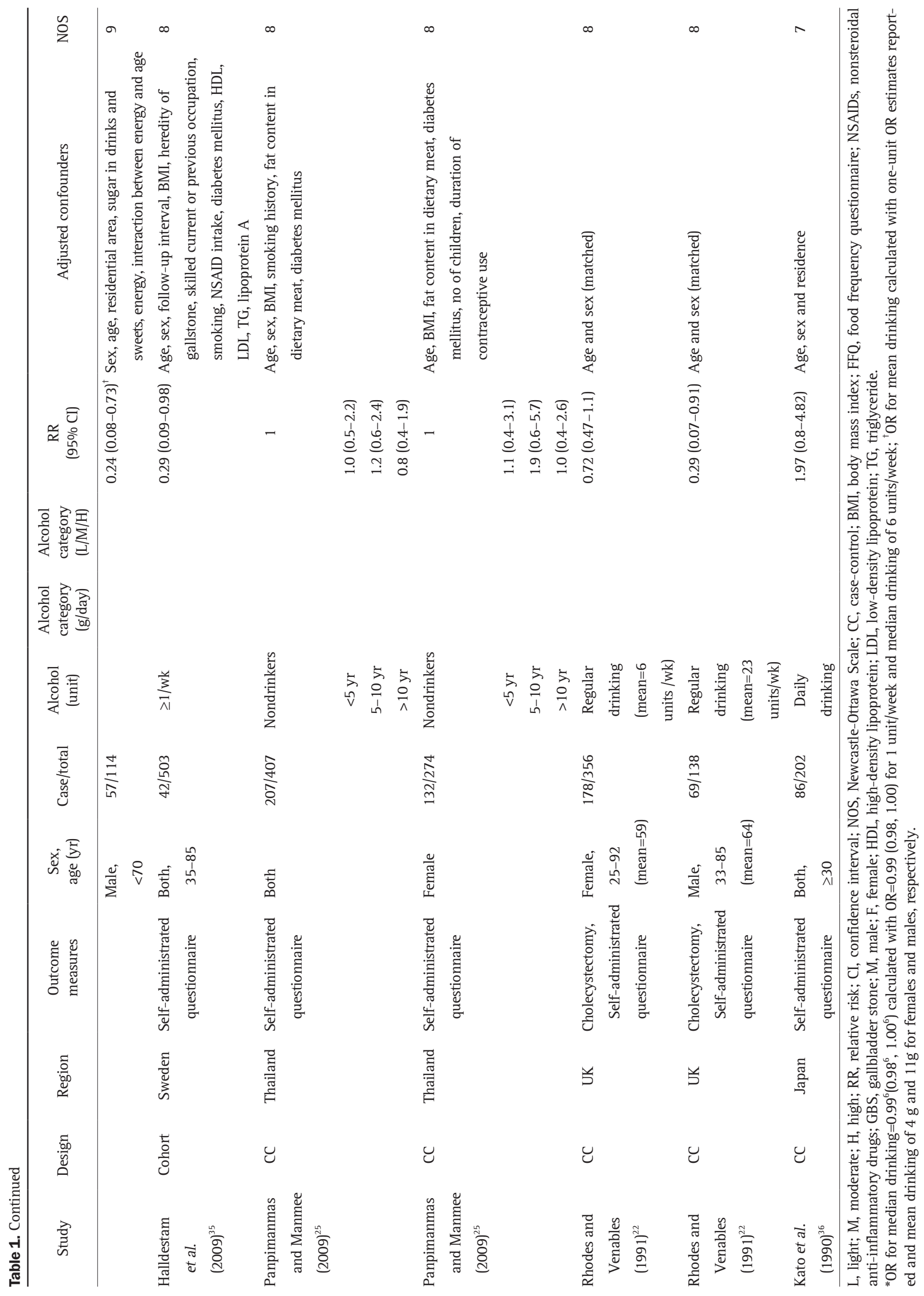


ascertainment of outcome or exposure, since their study populations were health professionals, nurses or twins; two studies used self-report for ascertainment of outcome, and the other had no description of ascertainment of exposure. One study was rated as 6 stars since it used self-report for ascertainment of exposure and outcome in nurses.

\section{Categorical meta-analysis}

\section{1) Overall drinking compared to nondrinking}

The pooled RR of GSD for alcohol drinking compared to non- drinking was 0.84 (95\% CI, 0.79 to $0.89 ; \mathrm{I}^{2}=61 \%$ ) based on 23 studies; only one of these studies included sex-adjusted effects for both sex groups (Fig. 2). ${ }^{25}$ The subgroup analyses by study design showed that there was a significant difference between study designs $(\mathrm{p}=0.02)$. The pooled analysis from case-control studies showed a greater decreased effect of drinking than that found in cohort studies. The pooled RR from studies with a cohort design was 0.89 (95\% CI, 0.84 to 0.89) with low heterogeneity between studies $\left(\mathrm{I}^{2}=28 \%\right)$, and the pooled RR from studies with a case-control design was 0.74 (95\% CI, 0.63 to 0.86) with

\section{Study, year}

Scragg et al, 1984

Scragg et al, 1984

Kato et al, 1990

La Vecchia et al, 1991

Rhodes \& Venables, 1991

Rhodes \& Venables, 1991

Thijs et al, study B1, 1991

Thijs et al, study B2, 1991

Thijs et al, study B3, 1991

Grodstein et al, 1994

Leizmann et al, 1999

Misciagna et al, 1999

Leitzmann et al, 2003

Katsika et al, 2007

Halldestam et al, 2009

Panpimanmas \& Manmee, 2009

Banim et al, 2011

Banim et al, 2011

Bodmer et al, 2011

Shabanzadeh et al, 2016

Cha et al, 2017

Cha et al, 2017

Random effects model

Heterogeneity: $I^{2}=61 \%, p<0.01$
Kato et al, 1992

$\begin{array}{ccc}\text { Sex } & \text { RR } & {[95 \% \mathbf{C l}]} \\ \text { F } & 0.51 & {[0.34 ; 0.78]} \\ \text { M } & 0.24 & {[0.08 ; 0.73]} \\ \text { B } & 1.97 & {[0.80 ; 4.82]} \\ \text { B } & 0.69 & {[0.48 ; 0.99]} \\ \text { F } & 0.72 & {[0.47 ; 1.10]} \\ \text { M } & 0.29 & {[0.07 ; 0.91]} \\ \text { B } & 1.01 & {[0.57 ; 1.81]} \\ \text { B } & 0.96 & {[0.52 ; 1.76]} \\ \text { B } & 0.78 & {[0.43 ; 1.43]} \\ \text { M } & 0.92 & {[0.76 ; 1.12]} \\ \text { F } & 0.80 & {[0.67 ; 0.94]} \\ \text { M } & 0.83 & {[0.72 ; 0.96]} \\ \text { B } & 0.69 & {[0.42 ; 1.14]} \\ \text { F } & 0.88 & {[0.84 ; 0.92]} \\ \text { B } & 0.77 & {[0.70 ; 0.85]} \\ \text { B } & 0.29 & {[0.09 ; 0.98]} \\ \text { B } & 1.00 & {[0.66 ; 1.53]} \\ \text { F } & 0.96 & {[0.67 ; 1.38]} \\ \text { M } & 0.98 & {[0.52 ; 1.85]} \\ \text { B } & 0.90 & {[0.87 ; 0.93]} \\ \text { B } & 0.94 & {[0.89 ; 1.00]} \\ \text { F } & 0.16 & {[0.05 ; 0.59]} \\ \text { M } & 0.30 & {[0.14 ; 0.64]} \\ & & \\ & \mathbf{0 . 8 4} & {[0.79 ; 0.89]}\end{array}$

Sex

F $\quad 0.51$

Sex $=F$

Scragg et al, 1984

Rhodes \& Venables, 1991

Grodstein et al, 1994

Leitzmann et al, 2003

Panpimanmas \& Manmee, 2009

Banim et al, 2011

Cha et al, 2017

Random effects model

Heterogeneity: $I^{2}=65 \%, p<0.01$

\section{Sex=M}

Scragg et al, 1984

Rhodes \& Venables, 1991

Kato et al, 1992

Leitzmann et al, 1999

Banim et al, 2011

Cha et al, 2017

Random effects mode

Heterogeneity: $I^{2}=68 \%, p<0.01$

Random effects model Heterogeneity: $\left.\right|^{2}=64 \%, p<0.01$

Test for subgroup differences: $\chi_{1}^{2}=0.55, \mathrm{df}=1 \quad(p=0.46)$
RR

$[95 \% \mathrm{Cl}]$

$[0.34 ; 0.78]$

$[0.47 ; 1.10]$

$[0.67 ; 0.94]$

$[0.84 ; 0.92]$

$[0.68 ; 2.22]$

$[0.67 ; 1.38]$

$[0.05 ; 0.59]$

0.16

0.79

$[0.66 ; 0.95]$

0.24

0.29

0.92

0.83

0.98

0.30

0.69

$[0.08 ; 0.73]$

$[0.07 ; 0.91]$

$[0.76 ; 1.12]$

$[0.72 ; 0.96]$

$[0.52 ; 1.85]$

$[0.14 ; 0.64]$

$[0.51 ; 0.93]$

0.78

$[0.68 ; 0.89]$

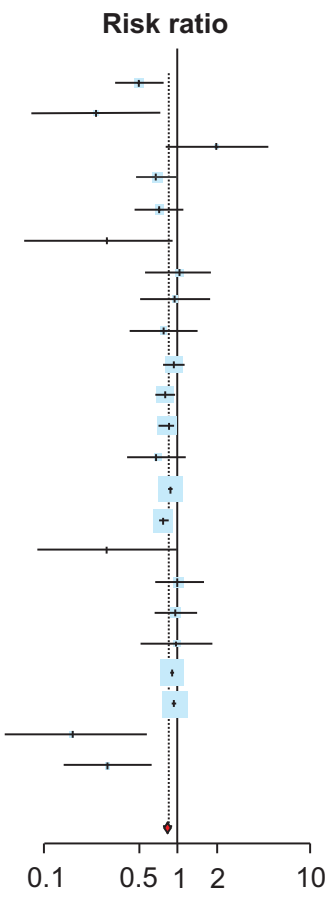

Fig. 2. Relative risks (RRs) of overall alcohol consumption for gallstone disease development $(\mathrm{n}=23)$. $\mathrm{CI}$, confidence interval; $\mathrm{F}$, female; $\mathrm{M}$, male, B, both.

\section{Risk ratio}

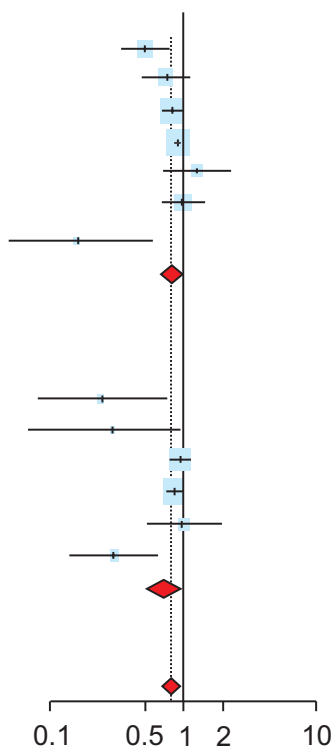

Fig. 3. Relative risks (RRs) of alcohol consumption for gallstone disease development among females and males $(n=21)$.

$\mathrm{CI}$, confidence interval; $\mathrm{F}$, female; $\mathrm{M}$, male. 
large heterogeneity $\left(\mathrm{I}^{2}=70 \%\right)$. The pooled RRs by sex were 0.79 (95\% CI, 0.66 to 0.95; $\mathrm{I}^{2}=65 \%$ ) for females and 0.69 (95\% CI, 0.51 to $0.93 ; \mathrm{I}^{2}=68 \%$ ) for males, with no significant difference between sex ( $p=0.46)$ (Fig. 3).

\section{2) Drinking categories compared to nondrinking}

Pooled analysis revealed that every alcohol consumption category was significantly associated with a decreased risk of GSD, with greater decreased risk in the higher alcohol consumption groups (Fig. 4). The pooled RRs for the light, moderate and high alcohol consumption groups compared to those in the nondrinking groups were 0.96 (95\% CI, 0.94 to $0.99 ; \mathrm{I}^{2}=0 \%$ ), 0.80 (95\% CI, 0.75 to $0.85 ; \mathrm{I}^{2}=17 \%$ ) and $0.66(95 \% \mathrm{CI}, 0.56$ to 0.79 ; $\left.\mathrm{I}^{2}=61 \%\right)$, respectively. The high alcohol consumption groups

Light

\section{Study, year}

Thijs et al, B1, 1991

Thijs et al, B2, 1991

Thijs et al, B3, 1991

Kato et al, 1992

Grodstein et al, 1994

Leitzmann et al, 1999

Misciagna et al, 1999

Leitzmann et al, 2003

Banim et al, 2011

Banim et al, 2011

Bodmer et al, 2011

Random effects model

Heterogeneity: $I^{2}=0 \%, p=0.75$

Moderate

La Vecchia et al, 1991

Thijs et al, B1, 1991

Thijs et al, B2, 1991

Thijs et al, B3, 1991

Kato et al, 1992

Grodstein et al, 1994

Leitzmann et al, 1999

Misciagna et al, 1999

Leitzmann et al, 2003

Banim et al, 2011

Banim et al, 2011

Bodmer et al, 2011

Cha et al, 2017

Cha et al, 2017

Random effects model

Heterogeneity: $I^{2}=17 \%, p=0.27$

High

\section{Study, year}

La Vecchia et al, 1991

Thijs et al, B1, 1991

Thijs et al, B2, 1991

Thijs et al, B3, 1991

Kato et al, 1992

Grodstein et al, 1994

Leitzmann et al, 1999

Misciagna et al, 1999

Leitzmann et al, 2003

Banim et al, 2011

Banim et al, 2011

Bodmer et al, 2011

Cha et al, 2017

Heterogeneity: $\mathrm{I}^{2}=61, \mathrm{p}<0.01$

\section{Study, year}

Cha et al, 2017

Random effects model showed the greatest decreased risk of GSD with significantly large heterogeneity between studies. In the subgroup analysis by study design, the pooled effects of moderate and high alcohol consumption in case-control studies were larger than those in cohort studies (Fig. 5).

\section{Dose-response meta-analysis}

The dose-response meta-analysis of 14 studies suggested a nonlinear relationship between alcohol consumption and risk of GSD from 14 studies ( $p=0.002$ for nonlinearity) (Fig. 6). The risk of GSD decreased with increasing alcohol consumption up to approximately $30 \mathrm{~g} / \mathrm{day}$, and the decrease in risk plateaued above $30 \mathrm{~g} /$ day. The RRs (95\% CIs) of GSD compared to nondrinking groups were 0.92 (0.89 to 0.95$)$, 0.82 (0.79 to 0.85 ), 0.67

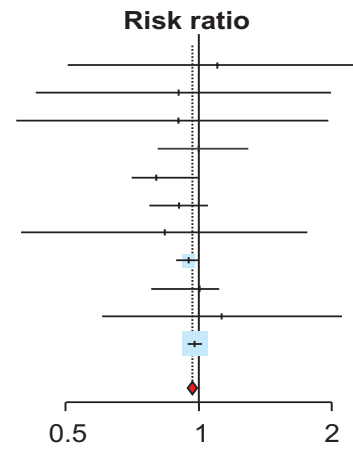

[95\% Cl]

[0.60; 1.30$]$

$[0.32 ; 1.60]$

$[0.45 ; 2.07]$

$[0.29 ; 1.39]$

$[0.70 ; 1.20]$

$[0.60 ; 1.00]$

$[0.60 ; 0.93]$

$[0.32 ; 1.67]$

$[0.80 ; 0.93]$

$[0.42 ; 1.24]$

$[0.21 ; 1.58]$

$[0.72 ; 0.80]$

$[0.06 ; 2.35]$

$[0.11 ; 0.85]$

$[0.75 ; 0.85]$

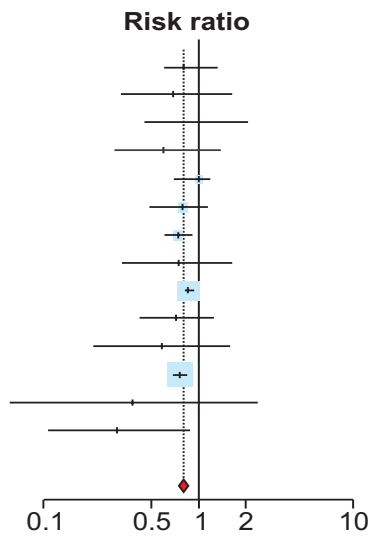

[95\% Cl]

[0.30;0.80]

$[0.63 ; 3.40]$

$[0.36 ; 2.60]$

$[0.43 ; 5.39]$

$[0.60 ; 1.00]$

$[0.40 ; 1.40]$

$[0.50 ; 0.81]$

$[0.14 ; 1.28]$

$[0.68 ; 0.80]$

$[0.54 ; 1.92]$

$[0.17 ; 1.25]$

$[0.46 ; 0.62]$

$[0.02 ; 0.53]$

$[0.11 ; 0.78]$

[0.56; 0.79]

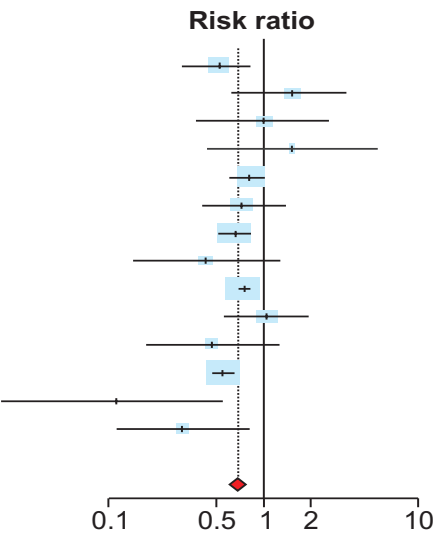

Fig. 4. Relative risks (RRs) of alcohol consumption for gallstone disease development based on alcohol drinking categories (light, moderate, and high). Drinking level for each category: light, $\mathrm{F}<7$ and $\mathrm{M}<14 \mathrm{~g} /$ day; moderate, F 7-17 and M 14-18 $\mathrm{g} /$ day; high, $\mathrm{F}>14$ and $\mathrm{M}>28 \mathrm{~g} /$ day. $\mathrm{CI}$, confidence interval; $\mathrm{F}$, female; $\mathrm{M}$, 
(0.64 to 0.71), and 0.62 (0.58 to 0.66 ), and 0.61 (0.52 to 0.71 ) for $7,14,28,40$, and $60 \mathrm{~g} /$ day of alcohol consumption, respectively. However, the dose-response results by study design showed that the nonlinear relationship between alcohol consumption and the risk of GSD was statistically significant in case-control studies but not in cohort studies ( $\mathrm{p}=0.001$ and $\mathrm{p}=0.184$ for nonlinearity in case-control and cohort studies, respectively).

\section{Publication bias}

Funnel plots and Egger's tests for overall drinking suggested significant asymmetry (Egger test $\mathrm{p}=0.009$ ) (Fig. 7). However, no significant asymmetries were found by alcohol consumption categories (Egger tests $p=0.383, p=0.523$, and $p=0.602$ for low-, moderate-, and high-consumption categories, respectively).

\section{Light}

\section{Study, year}

Study design=case-control

Thijs et al, B1, 1991

Thijs et al, B2, 1991

Thijs et al, B3, 1991

Misciagna et al, 1999

Bodmer et al, 2011

Random effects model

Heterogeneity: $I^{2}=0 \%, p=0.99$

\section{Study design=cohort \\ Kato et al, 1992 \\ Grodstein et al, 1994 \\ Leitzmann et al, 1999 \\ Leitzmann et al, 2003 \\ Banim et al, 2011 \\ Banim et al, 2011}

$\begin{array}{ccc}\text { Sex } & \text { RR } & {[95 \% \mathrm{Cl}]} \\ & & \\ \text { B } & 1.10 & {[0.50 ; 2.28]} \\ \text { B } & 0.90 & {[0.42 ; 2.01]} \\ \text { B } & 0.90 & {[0.38 ; 2.00]} \\ \text { B } & 0.83 & {[0.39 ; 1.78]} \\ \text { B } & 0.98 & {[0.95 ; 1.02]} \\ & \mathbf{0 . 9 8} & {[0.95 ; 1.01]}\end{array}$

Random effects model

Heterogeneity: $\left.\right|^{2}=0 \%, p=0.51$

Random effects model

Heterogeneity: $I^{2}=0 \%, p=0.75$

Test for subgroup differences $\chi_{1}^{2}=2.14, \mathrm{df}=1 \quad(p=0.14)$

$\begin{array}{ccc}\mathrm{M} & 1.00 & {[0.80 ; 1.30]} \\ \mathrm{F} & 0.80 & {[0.70 ; 1.00]} \\ \mathrm{M} & 0.90 & {[0.77 ; 1.04]} \\ \mathrm{F} & 0.95 & {[0.89 ; 1.00]} \\ \mathrm{F} & 1.01 & {[0.70 ; 1.46]} \\ \mathrm{M} & 1.13 & {[0.60 ; 2.13]} \\ & \mathbf{0 . 9 4} & {[0.89 ; \mathbf{0 . 9 8}]} \\ & & \\ & \mathbf{0 . 9 6} & {[\mathbf{0 . 9 4} ; \mathbf{0 . 9 9}]}\end{array}$

Moderate

$\quad$ Study, year
Study design=case-control
La Vecchia et al, 1991
Bodmer et al, 2011
Misciagna et al, 1999
Cha et al, 2017
Cha et al, 2017
Thijs et al, B1, 1991
Thijs et al, B2, 1991
Thijs et al, B3, 1991
Random effects model
Heterogeneity: ${ }^{2}=0 \%, p=0.70$

$\begin{array}{ccc}\text { Sex } & \text { RR } & {[95 \% \mathbf{C l}]} \\ \text { B } & 0.80 & {[0.60 ; 1.30]} \\ \text { B } & 0.76 & {[0.72 ; 0.80]} \\ \text { B } & 0.74 & {[0.32 ; 1.67]} \\ \text { F } & 0.38 & {[0.06 ; 2.35]} \\ \text { M } & 0.30 & {[0.11 ; 0.85]} \\ \text { B } & 0.70 & {[0.32 ; 1.60]} \\ \text { B } & 1.00 & {[0.45 ; 2.07]} \\ \text { B } & 0.60 & {[0.29 ; 1.39]} \\ & \mathbf{0 . 7 6} & {[\mathbf{0 . 7 2} ; \mathbf{0 . 8 0}]}\end{array}$

\section{Study design=cohort}

Kato et al, 1992

Grodstein et al, 1994

Leitzmann et al, 1999

Leitzmann et al, 2003

Banim et al, 2011

Banim et al, 2011

$\begin{array}{ccc}M & 1.00 & {[0.70 ; 1.20]} \\ \mathrm{F} & 0.80 & {[0.60 ; 1.00]} \\ \mathrm{M} & 0.75 & {[0.60 ; 0.93]} \\ \mathrm{F} & 0.86 & {[0.80 ; 0.93]} \\ \mathrm{F} & 0.72 & {[0.42 ; 1.24]} \\ \mathrm{M} & 0.58 & {[0.21 ; 1.58]} \\ & \mathbf{0 . 8 5} & {[\mathbf{0 . 8 0} ; \mathbf{0 . 9 1}]} \\ & & \\ & \mathbf{0 . 8 0} & {[\mathbf{0 . 7 5} ; \mathbf{0 . 8 5}]}\end{array}$

Random effects model

Heterogeneity: $I^{2}=0 \%, p=0.57$

Random effects model

$[0.75 ; 0.85]$

\section{DISCUSSION}

To estimate the association of alcohol consumption and GSD risk, we performed this meta-analysis of 16 case-control and eight cohort studies and found a significant dose-dependent, risk-reduction effect of drinking alcohol as a result (RR, 0.84; 95\% CI, 0.79 to 0.89 ).

There were two published meta-analyses regarding the correlation between alcohol consumption and gallstone development risk. ${ }^{78}$ One meta-analysis found no significant correlation between alcohol consumption and incidental gallstone risks. ${ }^{7}$ Another meta-analysis showed a statistically significant, inverse relationship between the highest and lowest consumption categories (RR, 0.62; 95\% CI, 0.49 to 0.78 ), whose pooled risk reduc-

Heterogeneity: $I^{2}=17 \%, p=0.27$

Test for subgroup differences $\chi_{1}^{2}=7.05, \mathrm{df}=1(p<0.01)$
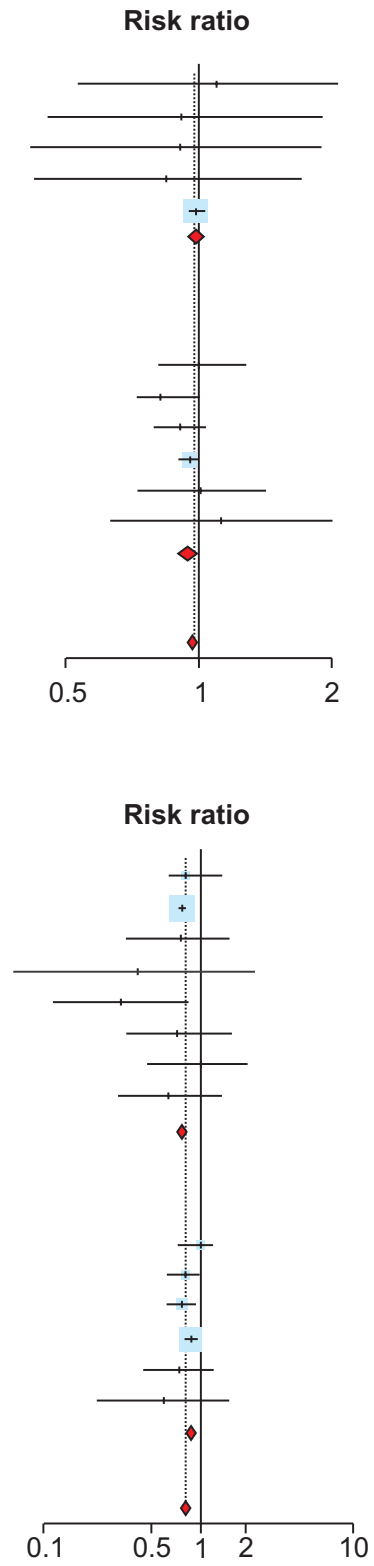

Fig. 5. Relative risks (RRs) of alcohol consumption for gallstone disease development based on alcohol drinking categories (light, moderate, and high) among case-control and cohort studies. Drinking level for each category: light, $\mathrm{F}<7$ and $\mathrm{M}<14$ g/day; moderate, F 7-17 and M 14-18 g/day; high, $\mathrm{F}>14$ and $\mathrm{M}>28$ g/day.

$\mathrm{CI}$, confidence interval; $\mathrm{F}$, female; $\mathrm{M}$, male, B, both. 
High

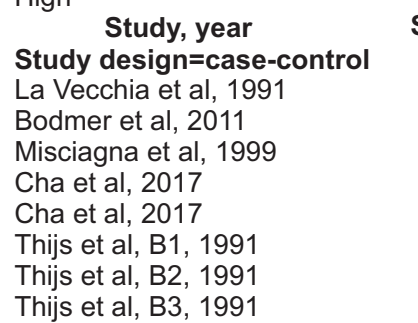

Random effects model

Heterogeneity: $\left.\right|^{2}=54 \%, p=0.03$

Study design $=$ cohort

Kato et al, 1992

Grodstein et al, 1994

Leitzmann et al, 1999

Leitzmann et al, 2003

Banim et al, 2011

Banim et al, 2011

Random effects model

Heterogeneity: $I^{2}=0 \%, p=0.61$

Random effects model

Heterogeneity: $I^{2}=61 \%, p<0.01$

Test for subgroup differences $\chi_{1}^{2}=1.33, \mathrm{df}=1 \quad(p=0.25)$

\subsection{8}

0.80

0.70

0.64

0.74

1.02

0.46

\subsection{3}

0.66

\section{[95\% Cl]}

$[0.30 ; 0.80]$

[0.46; 0.62]

$[0.14 ; 1.28]$

$[0.02 ; 0.53]$

$[0.11 ; 0.78]$

$[0.63 ; 3.40]$

$[0.36 ; 2.60]$

$[0.43 ; 5.39]$

$[0.40 ; 0.85]$

$[0.60 ; 1.00]$

$[0.40 ; 1.40]$

$[0.50 ; 0.81]$

$[0.68 ; 0.80]$

$[0.54 ; 1.92]$

$[0.17 ; 1.25]$

$[0.68 ; 0.79]$

$[0.56 ; 0.79]$

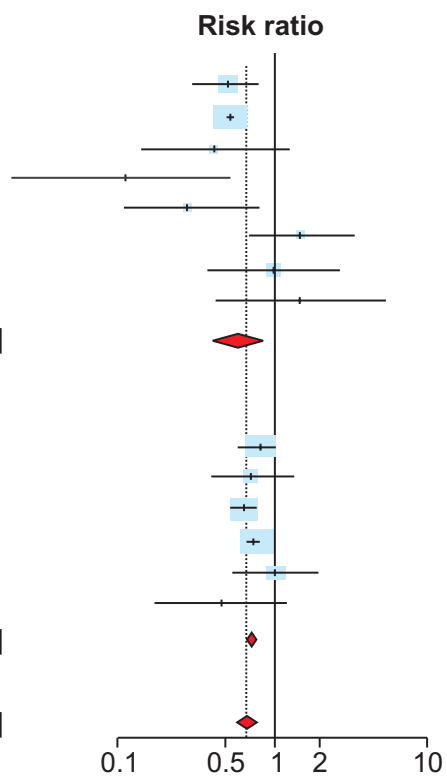

Fig. 5. Continued..
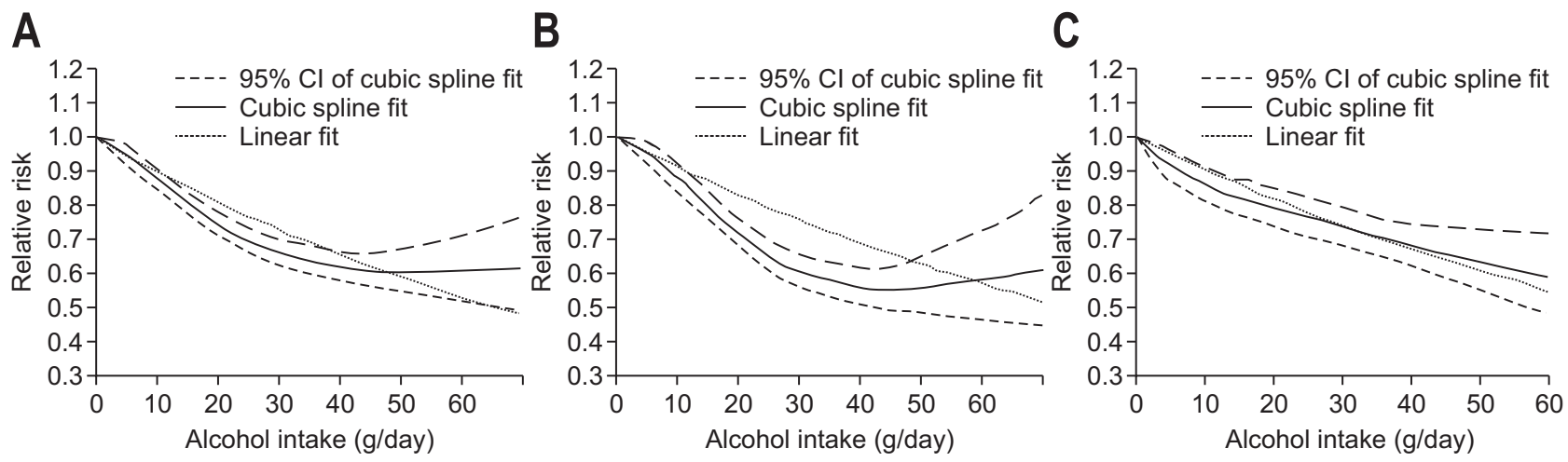

Fig. 6. Dose-response relationship between alcohol consumption and gallstone disease risk. (A) All included studies ( $n=14)$, $p$ for nonlinearity $<0.001$. (B) Case-control study ( $n=8), p$ for nonlinearity=0.001. (C) Cohort study $(n=6), p$ for nonlinearity=0.1839.

tion was larger than that of the overall drinking data relative to nondrinking or to the lowest category in this meta-analysis. ${ }^{8}$

Mechanisms underlying the protective effect of alcohol against gallstone formation have been explained in several ways: (1) decreased cholesterol saturation; ;7-39 (2) increased high-density lipoprotein by reduction of cholesteryl ester transfer protein; $;^{40-43}$ and (3) increased gallbladder motility. ${ }^{44-46}$

To discover the optimum level of alcohol drinking, we extracted quantitative alcohol consumption amounts with individual risk estimates in each category or continuous variables from each study and then sorted those data into new three categories: light, moderate, and high consumption. From the results, we obtained each different pooled RR according to the increment of alcohol consumption: 0.96 (0.94 to 0.99) in the light group; 0.80 (0.75 to 0.85 ) in the moderate group; 0.66 (0.56 to 0.79 ) in the high group. Furthermore, we carried out a dose-response meta- analysis for overall consumption and each subgroup of study design and sex. The RRs for GSD showed a weak trend between 28 and $40 \mathrm{~g} /$ day with a plateau occurring above $40 \mathrm{~g} /$ day, with RRs of 0.62 (0.58 to 0.66) and 0.61 (0.52 to 0.71) at 40 and 60 $\mathrm{g} /$ day, respectively. The dose-response relationship in casecontrol studies showed the same tendency as the overall group did, whereas a steady linear decline in RR for GSD was demonstrated in cohort studies, in which only two of the six studies had a drinking level of over $30 \mathrm{~g} /$ day.

Contrast to the former meta-analysis, we summarized the risk estimations measured by daily alcohol consumption according to standardized categories, which was comparable to different alcohol types based on the recommended statistical methods. ${ }^{12,16,17}$ Secondarily, we discovered a trend of linear decline in GSD risk according to an increase in alcohol consumption and a weakened linear trend between 28 and $40 \mathrm{~g}$ /day compared to 

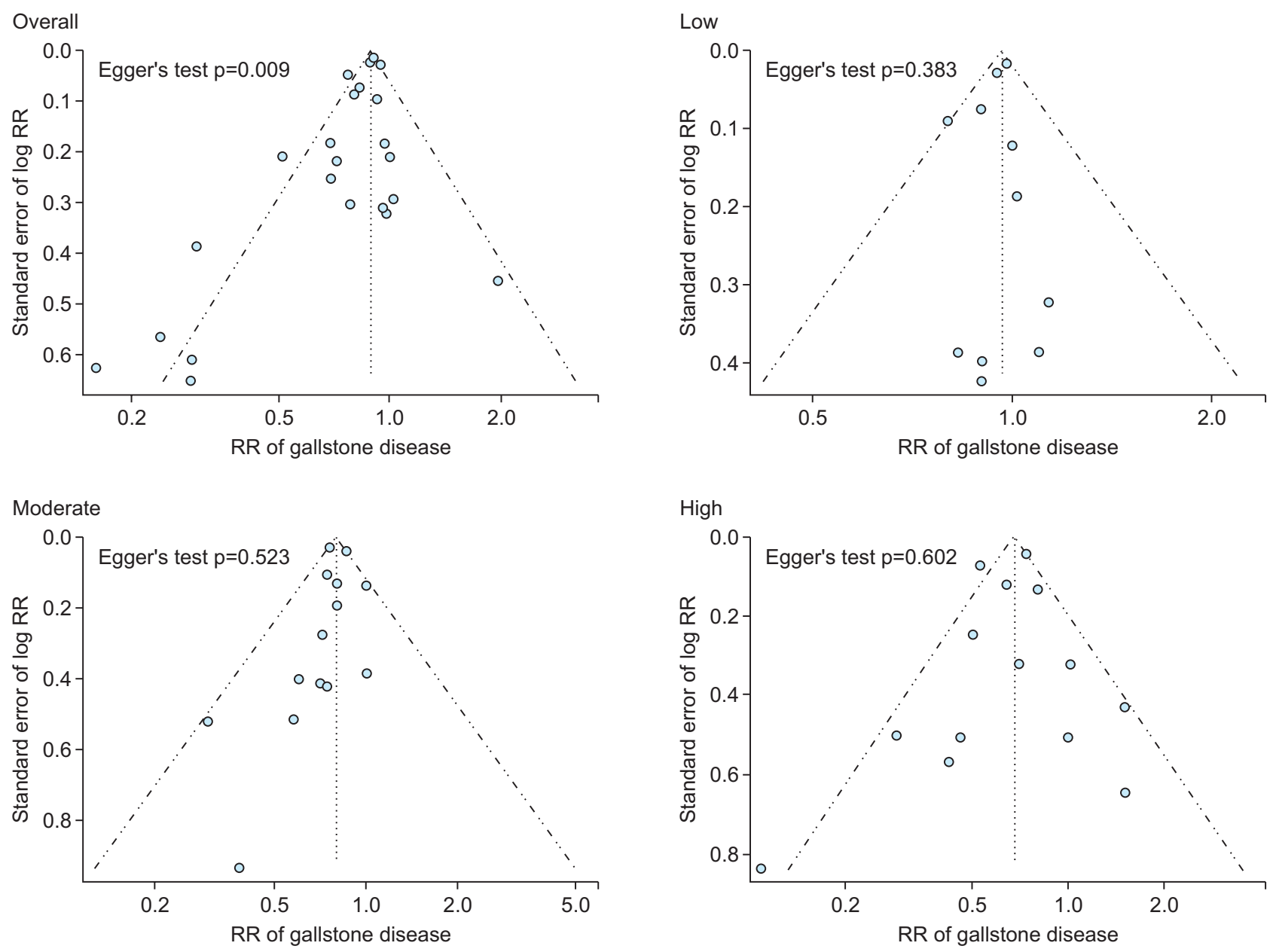

Fig. 7. Funnel plots of all included studies and different alcohol consumption levels. $\mathrm{RR}$, relative risk.

that of under $28 \mathrm{~g} /$ day in the overall and case-control studies but not in the cohort studies. The previous meta-analysis included one Asian study, which was completed in Thailand. We enrolled three more articles published in Asia (2 Chinese and 1 Korean), but two of them were cross-sectional studies; therefore, we included one more case-control study from Asia. ${ }^{24}$

There were limitations in our study. Although we achieved a nonlinear trend shown in the dose-response analysis among the overall studies and case-control studies, the same trend was not found among the cohort studies, which have the highest level of evidence. We attempted to enroll more studies published in various countries, for example, Asia, Africa, and South America; however, the majority of studies included for the dose-response meta-analysis were performed in North America and Europe due to newly published Asian studies having lower levels of evidence. Meanwhile, it was quite difficult to compare the quantitative alcohol effects in various beverage types and among the diverse individuals who are drinking in different ways, for example, in frequency and amount. Therefore, more important studies from varied regions and more comparable standardization methods are warranted to generalize the conclusions from our study.

In addition to the above limitations, clinicians need to be cautious in recommending drinking for the purpose of GSD prevention because excessive drinking, defined as binge drinking, and chronic heavy alcohol consumption results in multiple psychiatric and clinical illnesses, including mortality from a variety of chronic diseases. ${ }^{47-50}$

In conclusion, we confirmed that alcohol drinking decreases the risk of GSD development based on our meta-analysis of case-control and cohort studies. There was a linear risk reduction and weakened linear trend between consumption levels below and above $28 \mathrm{~g} /$ day in the dose-response analysis.

\section{CONFLICTS OF INTEREST}

No potential conflict of interest relevant to this article was reported.

\section{ACKNOWLEDGEMENTS}

Authors contributions: Two authors (B.H.C. and M.J.J.) per- 
formed a comprehensive systematic search for published studies which aimed to evaluate the relationship between alcohol consumption and gallstone disease risk. Data extraction was completed by two authors (B.H.C. and M.J.J.) independently from all included studies with a predefined information sheet, in accordance with the Preferred Reporting Items for Systematic Reviews and Meta-analyses. ${ }^{44}$ Any discrepancies in extracted data were solved through consensus or discussion with a third author (S.H.L.). The overall study quality was assessed independently by two authors (B.H.C. and M.J.J.) using the NewcastleOttawa Scale (NOS).

\section{REFERENCES}

1. Stinton LM, Shaffer EA. Epidemiology of gallbladder disease: cholelithiasis and cancer. Gut Liver 2012;6:172-187.

2. Everhart JE, Ruhl CE. Burden of digestive diseases in the United States part I: overall and upper gastrointestinal diseases. Gastroenterology 2009;136:376-386.

3. Shaffer EA. Epidemiology and risk factors for gallstone disease: has the paradigm changed in the 21st century? Curr Gastroenterol Rep 2005;7:132-140.

4. Andreotti G, Liu E, Gao YT, et al. Medical history and the risk of biliary tract cancers in Shanghai, China: implications for a role of inflammation. Cancer Causes Control 2011;22:1289-1296.

5. Ahrens W, Timmer A, Vyberg M, et al. Risk factors for extrahepatic biliary tract carcinoma in men: medical conditions and lifestyle: results from a European multicentre case-control study. Eur J Gastroenterol Hepatol 2007;19:623-630.

6. Bagnardi V, Rota M, Botteri E, et al. Alcohol consumption and site-specific cancer risk: a comprehensive dose-response metaanalysis. Br J Cancer 2015;112:580-593.

7. Shabanzadeh DM, Novovic S. Alcohol, smoking and benign hepato-biliary disease. Best Pract Res Clin Gastroenterol 2017;31:519527.

8. Wang J, Duan X, Li B, Jiang X. Alcohol consumption and risk of gallstone disease: a meta-analysis. Eur J Gastroenterol Hepatol 2017;29:e19-e28.

9. Park Y, Kim D, Lee JS, et al. Association between diet and gallstones of cholesterol and pigment among patients with cholecystectomy: a case-control study in Korea. J Health Popul Nutr 2017;36:39.

10. Moher D, Liberati A, Tetzlaff J, Altman DG; PRISMA Group. Preferred reporting items for systematic reviews and meta-analyses: the PRISMA statement. Int J Surg 2010;8:336-341.

11. Wells GA, Shea B, O’Connell D, et al. The Newcastle-Ottawa Scale (NOS) for assessing the quality of nonrandomised studies in metaanalyses [Internet]. Ottawa: Ottawa Hospital Research Institute [cited March 2017]. Available from: http://www.ohri.ca/programs/ clinical_epidemiology/oxford.asp.

12. Berlin JA, Longnecker MP, Greenland S. Meta-analysis of epidemiologic dose-response data. Epidemiology 1993;4:218-228.
13. Kloner RA, Rezkalla SH. To drink or not to drink? That is the question. Circulation 2007;116:1306-1317.

14. Kerr WC, Greenfield TK, Tujague J, Brown SE. A drink is a drink? Variation in the amount of alcohol contained in beer, wine and spirits drinks in a US methodological sample. Alcohol Clin Exp Res 2005;29:2015-2021.

15. National Institute on Alcohol Abuse and Alcoholism. The physicians' guide to helping patients with alcohol problems. Washington, DC: Government Printing Office, 1995.

16. Hamling J, Lee P, Weitkunat R, Ambühl M. Facilitating metaanalyses by deriving relative effect and precision estimates for alternative comparisons from a set of estimates presented by exposure level or disease category. Stat Med 2008;27:954-970.

17. Higgins JP, Thompson SG, Deeks JJ, Altman DG. Measuring inconsistency in meta-analyses. BMJ 2003;327:557-560.

18. Orsini N, Li R, Wolk A, Khudyakov P, Spiegelman D. Meta-analysis for linear and nonlinear dose-response relations: examples, an evaluation of approximations, and software. Am J Epidemiol 2012;175:66-73.

19. Orsini N, Bellocco R, Greenland S. Generalized least squares for trend estimation of summarized dose-response data. Stata J 2006;6:40-57.

20. Thijs C, Knipschild P, Leffers P. Does alcohol protect against the formation of gallstones? A demonstration of protopathic bias. J Clin Epidemiol 1991;44:941-946.

21. Scragg RK, McMichael AJ, Baghurst PA. Diet, alcohol, and relative weight in gall stone disease: a case-control study. Br Med J (Clin Res Ed) 1984;288:1113-1119.

22. Rhodes M, Venables CW. Symptomatic gallstones: a disease of non-smokers? Digestion 1991;49:221-226.

23. Banim PJ, Luben RN, Bulluck H, et al. The aetiology of symptomatic gallstones quantification of the effects of obesity, alcohol and serum lipids on risk. Epidemiological and biomarker data from a UK prospective cohort study (EPIC-Norfolk). Eur J Gastroenterol Hepatol 2011;23:733-740.

24. Cha BH, Lee BS, Lee SH, Kang SJ, Park MJ. A study of alcohol consumption and obesity as main risk factor for symptomatic gallbladder stone: a case-control study. Asian Pac J Cancer Prev 2017;18:715-719.

25. Panpimanmas S, Manmee C. Risk factors for gallstone disease in a Thai population. J Epidemiol 2009;19:116-121.

26. La Vecchia C, Negri E, D’Avanzo B, Franceschi S, Boyle P. Risk factors for gallstone disease requiring surgery. Int J Epidemiol 1991;20:209-215.

27. Kato I, Nomura A, Stemmermann GN, Chyou PH. Prospective study of clinical gallbladder disease and its association with obesity, physical activity, and other factors. Dig Dis Sci 1992;37:784790.

28. Grodstein F, Colditz GA, Hunter DJ, Manson JE, Willett WC, Stampfer MJ. A prospective study of symptomatic gallstones in women: relation with oral contraceptives and other risk factors. Obstet Gynecol 1994;84:207-214. 
29. Leitzmann MF, Giovannucci EL, Stampfer MJ, et al. Prospective study of alcohol consumption patterns in relation to symptomatic gallstone disease in men. Alcohol Clin Exp Res 1999;23:835-841.

30. Leitzmann MF, Tsai CJ, Stampfer MJ, et al. Alcohol consumption in relation to risk of cholecystectomy in women. Am J Clin Nutr 2003;78:339-347.

31. Bodmer M, Brauchli YB, Jick SS, Meier CR. Diabetes mellitus and the risk of cholecystectomy. Dig Liver Dis 2011;43:742-747.

32. Misciagna G, Centonze S, Leoci C, et al. Diet, physical activity, and gallstones: a population-based, case-control study in southern Italy. Am J Clin Nutr 1999;69:120-126.

33. Katsika D, Tuvblad C, Einarsson C, Lichtenstein P, Marschall HU. Body mass index, alcohol, tobacco and symptomatic gallstone disease: a Swedish twin study. J Intern Med 2007;262:581-587.

34. Shabanzadeh DM, Holmboe SA, Sørensen LT, Linneberg A, Andersson AM, Jørgensen T. Are incident gallstones associated to sex-dependent changes with age? A cohort study. Andrology 2017;5:931-938.

35. Halldestam I, Kullman E, Borch K. Incidence of and potential risk factors for gallstone disease in a general population sample. $\mathrm{Br} \mathrm{J}$ Surg 2009;96:1315-1322.

36. Kato I, Kato K, Akai S, Tominaga S. A case-control study of gallstones: a major risk factor for biliary tract cancer. Jpn J Cancer Res 1990;81:578-583.

37. Thornton J, Symes C, Heaton K. Moderate alcohol intake reduces bile cholesterol saturation and raises HDL cholesterol. Lancet 1983;2:819-822.

38. Schwesinger WH, Kurtin WE, Johnson R. Alcohol protects against cholesterol gallstone formation. Ann Surg 1988;207:641-647.

39. Kurtin WE, Schwesinger WH, Stewart RM. Effect of dietary ethanol on gallbladder absorption and cholesterol gallstone formation in the prairie dog. Am J Surg 1991;161:470-474.

40. Langer RD, Criqui MH, Reed DM. Lipoproteins and blood pressure as biological pathways for effect of moderate alcohol consumption on coronary heart disease. Circulation 1992;85:910-915.
41. Hagiage M, Marti C, Rigaud D, et al. Effect of a moderate alcohol intake on the lipoproteins of normotriglyceridemic obese subjects compared with normoponderal controls. Metabolism 1992;41:856861.

42. Gaziano JM, Buring JE, Breslow JL, et al. Moderate alcohol intake, increased levels of high-density lipoprotein and its subfractions, and decreased risk of myocardial infarction. N Engl J Med 1993;329:1829-1834.

43. Mukamal KJ, Jensen MK, Grønbaek M, et al. Drinking frequency, mediating biomarkers, and risk of myocardial infarction in women and men. Circulation 2005;112:1406-1413.

44. Probert CS, Emmett PM, Heaton KW. Some determinants of whole-gut transit time: a population-based study. QJM 1995;88:311-315.

45. Robles EA, Mezey E, Halsted CH, Schuster MM. Effect of ethanol on motility of the small intestine. Johns Hopkins Med J 1974;135:17-24.

46. Tsai TJ, Chan HH, Lai KH, et al. Gallbladder function predicts subsequent biliary complications in patients with common bile duct stones after endoscopic treatment? BMC Gastroenterol 2018;18:32.

47. Harwood H. Updating estimates of the economic costs of alcohol abuse in the United States: estimates, update methods, and data. NIH Publication no. 00-1583, Rockville: National Institute on Alcohol Abuse and Alcoholism, 2000.

48. Stahre M, Roeber J, Kanny D, Brewer RD, Zhang X. Contribution of excessive alcohol consumption to deaths and years of potential life lost in the United States. Prev Chronic Dis 2014;11:E109.

49. Edelman EJ, Fiellin DA. In the Clinic. Alcohol Use. Ann Intern Med 2016;164:ITC1- ITC16.

50. Moss HB, Chen CM, Yi HY. Prospective follow-up of empirically derived Alcohol Dependence subtypes in wave 2 of the National Epidemiologic Survey on Alcohol And Related Conditions (NESARC): recovery status, alcohol use disorders and diagnostic criteria, alcohol consumption behavior, health status, and treatment seeking. Alcohol Clin Exp Res 2010;34:1073-1083. 